DOI: http://dx.doi.org/10.22201/iie.18703062e.2003.82.2144

\author{
MICHEL CONAN \\ DUMBARTON OAKS
}

\title{
Nuevas tendencias de la historia de jardines y paisajes ${ }^{1}$
}

n MAYo de 1997, dos meses antes de mi llegada a Dumbarton 0 aks como director del área de estudios sobre jardines y paisajes, Joachim Wolschke-Bulmahn - mi predecesor en el puesto- organizó un coloquio sobre la historiografía de los jardines con la finalidad de conmemorar los 25 años de vida del programa en D umbarton 0 aks. ${ }^{2}$ Se trataba de llevar a

I. Fue un gran placer recibir la invitación del Instituto de Investigaciones Estéticas de la U niversidad Nacional Autónoma de M éxico para impartir esta conferencia y tener la oportunidad de presentar, entre distinguidos colegas, al gunos de los acercamientos a la historia de jardines y arquitectura paisajística que han sido introducidos en $\mathrm{D}$ umbarton $\mathrm{O}$ aks recientemente. Q uiero agradecer muchísimo a la doctora M aría Teresa U riarte por su amable invitación, y a Patricia Díaz Cayeros por ayudarme a preparar esta visita, por corregir mis faltas en castellano y también por su amistad.

2. D esde hace poco más de cinco años soy el director del área de estudios sobre jardines y paisajes en $\mathrm{D}$ umbarton $\mathrm{O}$ aks, una fundación norteamericana vinculada con la U niversidad de $\mathrm{H}$ arvard, aunque radicada en Washington, D.C. y no en Cambridge, M ass. Este texto presenta los resultados de algunos coloquios que tuvieron lugar en $\mathrm{D}$ umbarton $\mathrm{O}$ aks y que tuve la suerte de editar. Principalmente se trata de Perspectives on Garden H istories (1999), Environmentalism and Landscape Architecture (200o), Bourgeois and Aristocratic Cultural Encounters (2002) y Landscape D esign and the Experience of M otion (2003). Ya han sido publicados como libros y se pueden conseguir sin costo en el sitio de internet de Dumbarton 0 aks: <<www. doaks.org >> dirigiéndose a "Electronic Texts/H istory of Landscape Architecture". Se puede también obtener más información sobre $D$ umbarton 0 aks y sus becas de estudios doctorales y posdoctorales escribiendo a <४Landscape@doaks.org 》>. La publicación de los siguientes tres coloquios está en preparación: The N ew Horizons of Baroque Cultures, Sacred Gardens and Landscapes. Ritual and Agency y Profane Gardens and Landscapes. Performance and Appropria- 
cabo una retrospectiva, lo más completa posible, de los resultados que habían arrojado esos 25 años de trabajo, encuentros y debates sobre el tema. Lo Curioso es que todos los participantes, yo incluido, pensábamos que era más importante abordar el tema de las nuevas tendencias en la investigación que discutir sus logros. A todos nos resultaba evidente que un cambio radical estaba próximo. D urante los primeros diecisiete años, el rumbo de las investigaciones había sido muy claro: aprovechar los métodos de la iconografía para renovar y precisar los acontecimientos más importantes de la historia de los jardines de cada periodo. En ese entonces los coloquios se orientaron a estudiar los jardines italianos, los jardines formales franceses, lo pintoresco, los jardines islámicos, la arquitectura de paisaje de Frederick Law O Imsted, etcétera. A partir de 1990 se tuvo la impresión de que este modelo se estaba agotando, 0 al menos que había otros más interesantes a seguir. Sin embargo, no se plantearon nuevas aproximaciones en el coloquio de i997. iC ada estudioso miraba para su propio lado y parecía predicar en el desierto! Aun así, casi todos coincidíamos en reconocer el creciente influjo de la industria del turismo en el fantástico aumento de estudios de jardines históricos, tanto en Europa como en los Estados Unidos, o en países como Pakistán, y hasta cierto punto en China y Japón. Esta tendencia sigue siendo una constante en todas las naciones. D ebido a que a los turistas les gusta más visitar jardines que museos de arte contemporáneo, a muchos líderes les parece una buena inversión restaurar jardines históricos, para lo cual se requiere de la recuperación de los rasgos físicos y de la plantación que dichos jardines tenían en el pasado, bastando un breve estudio de la historia de su creación y de su iconografía. M uchas provincias en Inglaterra, Italia, Francia y Alemania se esfuerzan en contribuir a la historia de los jardines y han sustituido una historia de jardines regionalista por otra nacionalista. Sin embargo, los objetivos de la investigación siguen siendo los mismos que se desarrollaron a principios del siglo xx: el establecimiento de una tipología estilística; la ubicación de los jardines mejor logrados; la reivindicación regionalista de diseñadores y patrocinadores olvidados; el establecimiento de las trazas y los orígenes de las influencias estilísticas, así como de las contribuciones regionales al llamado "desarrollo del arte".

tion. En el primero se discuten asuntos sobre la recepción crítica del arte de los jardines y los paisajes, y los dos siguientes tratan sobre prácticas rituales en los mismos. En el presente texto me referiré a las fechas de presentación de las ponencias. En el sitio de internet se indican las fechas de su publicación. 
Cuando tuve que llevar a cabo la edición de las actas del coloquio de i997, me di cuenta de la presencia de un cambio de rumbo. En lugar de perseguir una historiografía dirigida hacia la construcción de un orgullo colectivo, los participantes del coloquio se habían beneficiado de varias preguntas propuestas por las ciencias humanas y sociales, la literatura, la sociología, la antropología e incluso la economía, para renovar sus aproximaciones históricas a los jardines y los paisajes. De este modo, la historia de los jardines se empezó a colocar dentro de una historia general de la cultura humana, aprovechándose de sus posibilidades de comparar culturas muy alejadas entre sí. Así, de manera muy significativa, la influencia estilística dejó de ser fuente de explicación para convertirse en objeto de investigación.

No cabe duda de que un cambio tan profundo tiene que darse paso a paso, y que éste corre paralelo al consumo de coffeetable books y mientras las visitas a jardines históricos restaurados impulsan el desarrollo de aproximaciones a la historia de jardines más conservadoras o tradicionalistas. Así, mirando hacia los últimos cinco años, me parece que destacan tres tipos de temas de estudio: las prácticas rituales, la recepción crítica del arte de los jardines y del paisajismo y, finalmente, la contribución de los jardines al cambio cultural. Al mismo tiempo, el recurrir a la arqueología para la restauración de jardines históricos ha contribuido a un crecimiento del interés en la arqueología de jardines y a un debate sobre el uso o abuso de los descubrimientos arqueológicos en nombre de la búsqueda de autenticidad.

\section{Prácticas rituales en jardines y paisajes}

Éste es el título de los dos más recientes coloquios que se han llevado a cabo en $\mathrm{D}$ umbarton $\mathrm{O}$ aks. El año pasado se presentaron ponencias sobre las prácticas de rituales sagrados en jardines y paisajes, y en el coloquio de este año se trató de rituales profanos. Desde hace algunos años, ciertos investigadores se han interesado en las prácticas sociales que tienen lugar dentro de jardines. M ientras los hechos individuales nos enseñen más sobre la personalidad de un individuo particular que sobre la cultura propia de sus contemporáneos, aquéllos no sirven para entender las prácticas ritualizadas que llevan a cabo los miembros de un grupo entero. Así, en el coloquio Ambientalismo en la arquitectura de paisaje, un profesor japonés, Taiichi Ito, atrajo la atención hacia las prácticas rituales dentro de los jardines aristócratas de la primera 
ciudad imperial, H eian-Ko, hoy en día Kyoto (1998). ${ }^{3}$ Estas prácticas rituales contribuyeron a destacar una nueva percepción de la naturaleza. Las nuevas prácticas estéticas durante visitas al campo en las afueras de la ciudad y los concursos de flores y cantos en los jardines fueron una reacción contra las pesadas condiciones de vida en la corte urbana de H eian-ko. El profesor japonés demostró también cómo esta apreciación colectiva de la naturaleza se perdió en los siglos siguientes con el abandono de esas prácticas rituales, que cedieron su lugar a una apreciación individual de los jardines a través de la mirada solitaria. El año siguiente (1999), Chandra M ukerji propuso que tanto las técnicas de agrimensura y de levantamiento de planos como las nuevas prácticas agrícolas contribuyeron, a fines del siglo xvi, a la expansión de las redes comerciales e introdujeron modos burgueses de pensamiento en el manejo de las grandes propiedades rurales de la aristocracia, influyéndola de manera inconsciente. Aunque se trate de asuntos del todo diferentes, en ambos casos, el estudio de las prácticas ritualizadas permite comprender la formación de ideas compartidas por mucha gente y su impronta en sus hábitos mentales. Así, hay investigadores que buscan cómo es que nuevas ideas 0 nuevos rasgos culturales brotan como consecuencia de nuevas prácticas sociales dentro de los jardines.

En esta categoría de investigación se encuentran los ensayos de Elizabeth $\mathrm{H}$ yde (1999) sobre el gusto por las flores en la Francia del siglo xvir; el desarrollo de un sentido popular de orgullo nacional en la Gran Bretaña de mediados del siglo xviII, por G regory N osan (1999); la edificación de una ética burguesa y de una oposición política al absolutismo austriaco durante el periodo Biedermeier en Viena (Robert Rotenberg, 1999); la catarsis de las angustias vinculadas a la navegación dentro de los jardines acuáticos de los emperadores romanos (Anne Kuttner, 1999); la metamorfosis del tiempo y del espacio del presente a un tiempo y espacio mítico cuando los participantes recrean una narrativa mítica a través de los rumbos y prácticas rituales que escenifican en un cierto lugar ( $M$ ichel Conan, 1999); o la producción de una cultura popular de consumo en Kaifeng, la capital china del siglo xiI (Stephen West, 2000). Todas estas investigaciones muestran las prácticas rituales dentro de jardines y paisajes, así como los gestos, los discursos y las emocio- 
nes que vienen a ser compartidos por todos, propiciando nuevas formas culturales sin que los actores de este cambio se den cuenta de ello.

Este tipo de estudio necesita dos aproximaciones diferentes: por un lado, el estudio de prácticas nuevas de personas 0 , mejor dicho, de un grupo de personas dentro de los jardines y, por otro lado, el estudio de la formación de los nuevos rasgos culturales que comparten esas personas. No basta con describir las prácticas individuales de los visitantes de un jardín, también es necesario tomar en cuenta los cambios culturales dentro de su sociedad, vinculados tanto con su horizonte de percepción y de entendimiento (aquí me refiero a la fenomenología) como con las interacciones entre esas personas (aquí me refiero a la sociología interaccionista). Por ejemplo, se pueden buscar vínculos entre el desarrollo de la idea de moda en la vestimenta (un rasgo cultural nuevo en el París de fines del siglo xviI), y el horizonte de percepción y de entendimiento de las prácticas de los miembros de la burguesía y la nobleza en sus paseos por la gran Allée des Tuileries dentro de la segunda mitad de dicho siglo.

La recepción crítica del arte del jardín y del paisaje

El simposio de 1998 trató sobre el impacto de los esfuerzos a favor del medio ambiente a lo largo del desarrollo de la arquitectura de paisaje. Éste obligó a hacer un estudio crítico de la distancia existente entre los efectos esperados y los propiciados por unos proyectos paisajísticos concebidos para difundir ideas en torno a la protección del medio ambiente.

D os autores demostraron, sin lugar a dudas, cómo grandes obras de ingeniería civil realizadas en Estados U nidos en los años treinta contribuyeron al desarrollo del consumo turístico, cuando su propósito era mostrar los provechos de la política federal a favor del resguardo colectivo del medio ambiente (G regory Cushman, 1998; Brian Black, I998). Q uedó muy claro que la recepción que el público tenía de un paisaje podía seguir criterios del todo diferentes a los propuestos por su diseñador. En el mismo simposio, Paul Kelsch mostró cómo la recepción del público de Nueva York de Time Landscape (una selva diminuta que ilustraba el desarrollo ecológico de la península de $M$ anhattan) contribuyó a una reinterpretación de la obra e impuso importantes cambios en este parque público. La obra (T ime Landscape) intentaba mostrar cómo tres tipos de ecosistemas se desarrollan cuando la naturaleza 
actúa por sí sola, pero al gunos habitantes del barrio alrededor del parque (T ime Landscape) decidieron cuidarlo, arrancando "hierbas malas" en la primavera y el verano, y barriendo las hojas muertas en el otoño.

0 tras ponencias atrajeron la atención hacia los cambios en la recepción de jardines en Bristol durante el siglo xviii, o el modo de apreciación del paisaje al pasar de la alta Edad M edia al periodo post-renacentista. Stephen Bann explicó cómo el estudio de un artista paisajista contemporáneo, el francés Bernard Lassus, le había permitido darse cuenta del sentido del tacto frente a la naturaleza expresado en la pintura alemana anterior al siglo xvir. Así, Bann abría la posibilidad de iluminar al gunos rasgos estéticos de obras del pasado, refirién dose a criterios destacados mucho más tarde.

Esto dirige la atención hacia los esfuerzos de la escuela de estudios literarios de Konstanz, que en los años sesenta se concentró en destacar un modo de juicio estético utilizando la historia de los juicios estéticos de cada obra de literatura bajo estudio. Seaprovechó este modelo para estudiar jardines. La idea es muy sencilla, aunque los presupuestos filosóficos, sacados del pensamiento de $\mathrm{H}$ ansG eorg G adamer, no lo sean: el juicio estético sobre una obra varía en el tiempo cuando la perspectiva de juicio, o sea el horizonte de percepción de la obra, ha cambiado atrayendo la atención hacia otros aspectos de la misma. Eso quiere decir que cada nuevo modo dejuicio correspondetanto a un nuevo ámbito cultural como a un aspecto específico de la propia obra. Así, el nuevo juicio puede describir aspectos de ella desconocidos hasta entonces. Pero las cosas no son tan fáciles, porque el juicio de un periodo determinado refleja, al mismo tiempo, tanto un posible rasgo distintivo de la obra como un ámbito cultural que no pertenece a la obra misma sino - más bien - a todos los hombres de ese tiempo posterior a su creación. Así, para demostrar la existencia de nuevos rasgos en la obra, la historia del arte tiene que llevar a cabo un estudio historicista y crítico del juicio expresado sobre ella. D e estemodo, se pueden descubrir sus rasgos artísticos a los que respondieron sucesivos juicios estéticos a lo largo del tiempo. Éste fue el rumbo de investigación que tomó el simposio sobre la apreciación de los jardines de la época barroca en el año 200I. Se destacaron particularmente las ponencias de Tracy Ehrlich quien, al iluminar el uso del modo de juicio inglés de mediados del siglo xviri, se dio cuenta de que los Borghese ya habían inventado la arquitectura de paisaje bucólica en la finca de la Villa Borghese en Tívoli a principios del siglo xvir; y también la ponencia de M argherita Azzi V isentini sobre tres siglos de juicios estéticos acerca de las islas Borromeas en el Lago M ayor. M ás recientemente, tuve la oportunidad de aprovechar este 
método para llevar a cabo un estudio de los jardines de Versalles que será publicado en Garten Kunst este año.

\section{Las políticas de cambio cultural}

En cierto modo, es posible decir que el diálogo entre la historia de losjardinesy la historia general de la cultura se limita a asuntos muy específicos de las ciencias sociales; es decir, al impacto de prácticas rituales sobre el desarrollo cultural, y al impacto de la cultura sobre el juicio estético. Se trata deinfluencias unívocas entrejardines y cultura. Sin embargo, al gunos investigadores se interesan en vínculos más amplios entre el desarrollo de la cultura paisajística y el desarrollo de la sociedad. No se trata, pues, solamente del estudio de un jardín por sí mismo, sino del estudio de una serie de jardines o paisajes, de sus creaciones y cambios, dentro de un periodo histórico bien definido. Así, por ejemplo, Brian Black mostró cómo el uso de la arquitectura de paisaje fue utilizado como instrumento pedagógico por el gobierno federal de los Estados U nidos en el periodo del Ilamado N ew D eal. Se trató de atraer turistas de los grandes centros urbanos del noreste hacia las montañas de Tennessee con el fin de hacerles descubrir los provechosos efectos del mejoramiento ambiental logrados por la TennesseeValley Authority (TVA) que actuaba en nombre del gobierno. Con este objetivo, la dirección de la planeación fue encargada a un arquitecto de paisaje, y los nuevos paisajes establecidos por la TVA reflejaban la concepción federal del medio ambiente entendido como "bien público". Se esperaba convencer a los turistas que visitaban los lagos artificiales de Tennessee, con sus plantas hidroeléctricas rodeadas de selvas recientemente plantadas, de que los esfuerzos de control ambiental por parte del gobierno federal resultaban provechosos para todos los ciudadanos norteamericanos, y no sólo para los de Tennessee. El esfuerzo ideológico fracasó, pero su estudio ilustra los estrechos vínculos entre la arquitectura depaisaje, la política federal y el cambio económico en los años del $\mathrm{N}$ ew $D$ eal. Stephen D anielsiluminó otro aspecto en el mismo simposio con un estudio de los esfuerzos que hizo $\mathrm{H}$ umphrey Repton por reformar la masculinidad de la aristocracia inglesa mientras se aprovechaba del desarrollo de una nueva sensibilidad femenina dentro de la misma aristocracia. Este proyecto tampoco funcionó e hizo que Repton se sintiera total mente fracasado al final de su vida. La ponencia de Lauro M agnani, por el contrario, mostraba tanto vínculosfallidos como exitosos entreel arte del jardín y las luchas políticas durante dos siglos 
en la República de Génova. A principios del siglo xvir, un nuevo modelo de villa con jardín fue establecido como símbolo del poder de una nueva aristocracia del comercio en la República de Génova y del cambio de sus intereses, que había pasado del comercio a larga distancia hacia el préstamo bancario a las cortes de Europa. Por más de un siglo, esto tuvo mucho éxito. A mediados del siglo xviII, un gobernador de la ciudad se atrevió a proponer otro modelo de economía para la República. Al darse cuenta de las dificultades de convencer a los otros ciudadanos, trató de mostrar con un jardín de estilo inglés sus nuevos presupuestos; sin embargo, fracasó tanto en el orden simbólico como en el orden político. Al año siguiente (200o), Lucia Tongiorgi Tomasi expuso el papel desempeñado por los creadores de los primeros jardines botánicos en Europa en el establecimiento de una red internacional de sabios y el desarrollo del nuevo espíritu científico. En este caso, es claro que los jardines reflejaron tanto el nuevo espíritu cuanto actuaron sobre su desarrollo, y que los sabios botánicos se aprove charon del apoyo de las monarquías del barroco para conformar una "república de sabios", la llamada "república de las letras".

Sería posible dar muchos ejemplos más: los vínculos entre las transformaciones de la burguesía y de la nobleza inglesa (a fines del siglo xviri) y el arte de jardines paisajísticos (Patrick Eyres, I999); la relación entre el florecimiento del nenúfar Victoria Regia (a cargo de Paxton) y el desarrollo de un nuevo modo de educar a las señoritas inglesas - el "nurturing" - en el siglo xix ( $M$ argaret $D$ arby, 1999); o bien la conexión entre la apertura del jardín imperial del oeste en Kaifeng en el siglo xiı y el desarrollo del consumo ostentoso dentro del pueblo de la capital china (Stephen West, 200o). Todas estas ponencias demuestran, por un lado, la existencia de vínculos entre la creación y uso de jardines y los cambios sociales, económicos o políticos que no pueden aclararse remitiéndose exclusiva o principalmente a las intenciones de los diseñadores 0 artistas que les dieron vida. Por otro lado, iluminan el papel desempeñado por esos jardines en muchos aspectos del cambio cultural, trazando nuevas dimensiones significativas del arte del jardín.

N uevos empeños en la arqueología de jardines

D esde hace mucho tiempo, los arqueólogos se dieron cuenta de la presencia de jardines dentro de los lugares en donde llevaban a cabo sus investigaciones, pero no fue hasta hace unos cuarenta años cuando pensaron que era posible 
descubrir rasgos significativos en ellos. Las investigaciones más recientes en Pompeya (Italia), Japón, Gran Bretaña, e incluso en los Estados Unidos, lo han demostrado. D umbarton $O$ aks ha encargado a dos arqueólogas, W ilhelmina Jashemski y Aicha M alek, la preparación de un libro que recopile los métodos utilizados por la arqueología de jardines, con la finalidad de que sean aprovechados por arqueólogos que no necesariamente sean especialistas en la historia de jardines. Se trata de ampliar el espectro de información que pueda obtenerse de una investigación arqueológica dentro de un sitio en donde hay tanto construcciones como jardines. Así, por ejemplo, el trabajo de Leigh Ann Bedal en Petra ha demostrado que la supuesta "plaza del mercado" dentro de este centro urbano, lugar de comercio a larga distancia, fue realmente un jardín palaciego. Ella piensa, además, que posteriormente - en tiempos de los romanos- se transformó en un jardín público. Este hallazgo obliga a una revisión de la lectura del sitio entero, y de la vida pública dentro de esta ciudad. Es posible acceder a las más recientes investigaciones sobre este sitio a través de la página internet de $\mathrm{D}$ umbarton $\mathrm{O}$ aks, en donde también se presentan los nuevos métodos de "non penetrating radar". Este método de investigación se puede usar para empezar un trabajo arqueológico sobre un terreno extenso, y escoger en él unos cuantos lugares en donde una excavación en busca de rasgos físicos será más exitosa. † 